
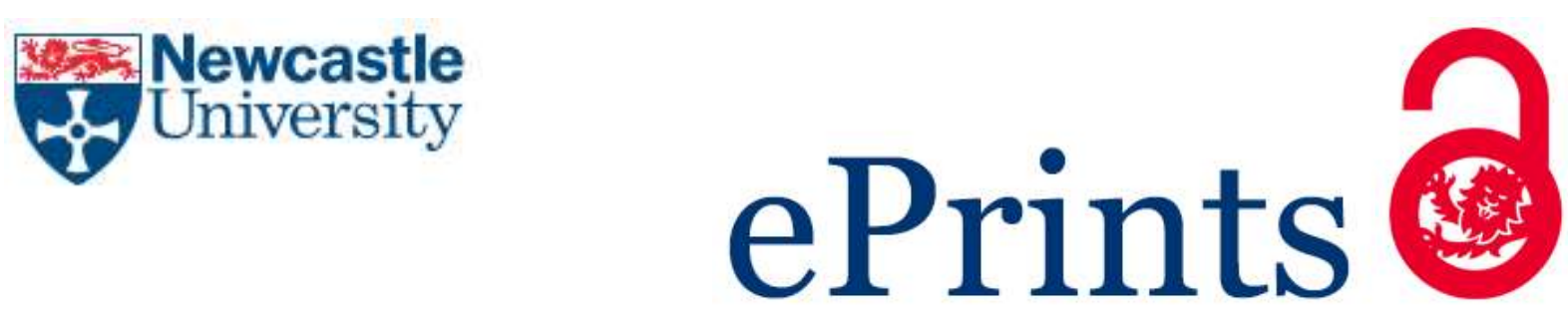

Williams TA, Foster PG, Cox CJ, Embley TM. An archaeal origin of eukaryotes supports only two primary domains of life. Nature 2013, 504, 231-236.

\title{
Copyright:
}

The final publication is available at Nature via http://dx.doi.org/10.1038/nature12779

Date deposited:

$29 / 09 / 2016$

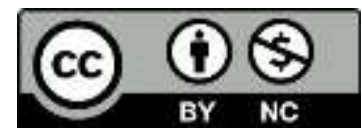

This work is licensed under a Creative Commons Attribution-NonCommercial 3.0 Unported License 


\section{An archaeal origin of eukaryotes supports only two primary domains of life}

Tom A. Williams ${ }^{1}$, Peter G. Foster ${ }^{2}$, Cymon J. Cox $^{3}$, T. Martin Embley ${ }^{1 *}$

*Corresponding author: Martin.Embley@ncl.ac.uk

\section{Author affiliations}

1. Institute for Cell and Molecular Biosciences, University of Newcastle, Newcastle upon Tyne NE2 4HH, United Kingdom.

2. Department of Life Sciences, Natural History Museum, London SW7 5BD, United Kingdom.

3. Centro de Ciências do Mar, Universidade do Algarve, Campus de Gambelas, 8005-139 Faro, Portugal. 


\section{Preface}

The discovery of the Archaea and the proposal of the three-domains "universal" tree based on ribosomal RNA and core genes mainly involved in protein translation catalyzed new ideas for cellular evolution and eukaryotic origins. But accumulating evidence suggests that the three-domains tree may be incorrect: evolutionary trees made using better methods place eukaryotic core genes within the Archaea, supporting hypotheses in which an archaeon participated in eukaryotic origins by founding the host lineage for the mitochondrial endosymbiont. These results provide support for only two primary domains of life: Archaea and Bacteria, because eukaryotes arose through partnership between them.

\section{Introduction}

Since their discovery by Carl Woese and his co-workers in 1977, the Archaea have figured prominently in hypotheses for eukaryotic origins ${ }^{1,2}$. Though similar to Bacteria in terms of cell structure, molecular phylogenies for ribosomal RNA and a small core of genes, that mainly play essential roles in protein translation ${ }^{3}$, suggested that the Archaea were more closely related to the eukaryotic nuclear lineage; that is, to the host cell that acquired the mitochondrion ${ }^{4}$. The idea that Archaea and eukaryotes are more closely related to each other than either is to Bacteria depends on analyses suggesting that the root of the tree should be placed on the bacterial stem, or within the Bacteria ${ }^{5-12}$, implying that the prokaryotes - cells that lack a nucleus - are a paraphyletic group ${ }^{13}$. The main question now debated is whether core components of the eukaryotic nuclear lineage descend from a common ancestor shared with Archaea, as in the three-domains tree ${ }^{14}$ (Figure 1) which is also often called the "universal tree" or "tree of life"15-17, or from within the Archaea, as proposed by archaeal-host hypotheses for eukaryotic origins ${ }^{2}$. The archaeal-host scenario with the greatest phylogenetic support is the eocyte hypothesis ${ }^{18}$, which proposes a sister group relationship between eukaryotes and the eocytes (or Crenarchaeota ${ }^{14}$ ), one of the major archaeal divisions (Figure 1). But the three-domains-eocyte debate remains controversial because different phylogenetic methods have delivered different results, 
often from the same data ${ }^{19}$. This disagreement is due, at least in part, to the difficulties associated with resolving ancient divergences in phylogenetic trees.

\section{Challenges of reconstructing ancient relationships}

A major issue in reconstructing ancient relationships is the strength and quality of historical signal remaining after the millions of years since the divergence of Archaea and eukaryotes. The earliest fossils identified as eukaryotic appeared by about 1.8 billion years $\mathrm{ago}^{20}$; over this enormous span of time, the accumulation of multiple substitutions in DNA and protein sequences might have erased any signal that would allow the relationship between archaeal and eukaryotic core genes to be established ${ }^{21}$. However, more recent simulations and empirical studies suggest there are reasons to be cautiously optimistic that this is not the case: functional constraints vary across real DNA and protein sequences so that sites evolve at different rates ${ }^{22-25}$. Fast evolving sites are indeed quickly saturated but the slowest sites can still retain useful phylogenetic information, explaining why we are able to align some genes over the entire tree of life. Analyses of molecular sequences might therefore be able to distinguish between the alternative hypotheses for eukaryotic core gene origins, but the phylogenetic methods used and the types of data analyzed are likely to be of critical importance in attempts to recover any historical signal ${ }^{22-26}$.

The problems associated with phylogenetic reconstruction come into particularly sharp focus when comparing support for the three-domains and eocyte trees. The first studies to investigate this question generally recovered the threedomains tree, in which eukaryotes emerge as the sister group to Archaea ${ }^{27,28}$, but the parsimony and distance methods used carried unrealistic assumptions, including constancy (homogeneity) of base compositions across lineages and of evolutionary rates across sites. These assumptions are clearly violated by key phylogenetic markers such as small subunit rRNA genes, which contain a mixture of fast- and slowlyevolving sites ${ }^{29}$ and for which GC-content varies widely among the three domains ${ }^{12}$. Compositional heterogeneity can cause phylogenetic error when not taken into account, because sequences of similar base or amino acid composition may group together in the tree even when they are not closely related ${ }^{30-32}$. Two pioneering studies used methods to mitigate possible convergence in the universal tree due to shared 
compositional biases in nucleotide sequences and, interestingly, both recovered an eocyte tree ${ }^{33,34}$.

Long branch attraction (LBA) is another pervasive artifact in molecular phylogenies, in which sequences with long branches cluster together irrespective of their evolutionary history ${ }^{25,35}$. LBA is especially problematic for parsimony methods, but it can also affect probabilistic methods if the model ignores among-site rate variation, or is otherwise a poor fit to the data ${ }^{36}$. Trees for the ribosomal RNA and protein-coding genes used to infer relationships between domains often show evidence of long branches and are therefore susceptible to LBA. Some of the early attempts to mitigate the influence of LBA in inter-domain analyses also recovered eocyte trees, although with variable support. Evolutionary parsimony, a method designed to reduce the effect of long branches on the inferred tree, recovered an eocyte topology from rRNA sequences ${ }^{37}$, although archaeal monophyly was favoured when a related method, compositional statistics, was used to analyze RNA polymerase sequences ${ }^{38}$. By contrast, analyses of rRNA and RNA polymerase using models that accounted for among-site rate variation supported the eocyte hypothesis over the three-domains tree ${ }^{39}$. To reconcile these results, Tourasse and Gouy ${ }^{39}$ suggested that the three-domains tree might be a phylogenetic artifact caused by LBA between the long bacterial and eukaryotic branches, forcing an artifactual clustering of the shorter archaeal branches. In other words, the eocyte tree might be intrinsically more difficult to recover using simple methods, because it requires the clustering of the short branch leading to the eocytes/Crenarchaeota with the long eukaryotic branch.

Single gene phylogenies often fail to strongly resolve the relationships between the domains ${ }^{12,40}$, and so in order to bring more characters to bear on the problem, a number of studies have analyzed concatenations of the core set of proteins conserved on all genomes. As already described, these genes largely function in translation and gene expression, and include many of the essential RNA and protein components of the ribosome. These cellular components have been called the "genealogy-defining core" 3 , the "genetic core" 41 of cells or the "functional core of genomes"16, and their common history has been cited $^{3,16,41}$ as the strongest support for the three-domains tree. Testing the evolutionary origins of this small set of genes is 
therefore critical to the three-domains-eocyte debate. Interestingly, analyses using similar sets of concatenated core genes have yielded different conclusions - for example Katoh et al. ${ }^{42}$ obtained an eocyte tree from a set of 39 universal proteins, whereas Ciccarelli et al. $^{43}$ analyzed a similar set of proteins and obtained a threedomains tree. One reason for the conflicting results in this case may be the different methods used for making the sequence alignment: the order of alignment had previously been shown to dictate which tree (eocyte or three-domains) was recovered from elongation factor Tu sequences ${ }^{44}$. Ciccarreli et al. ${ }^{43}$ aligned bacterial, archaeal and eukaryotic sequences separately before combining them into a single alignment. This step-wise procedure was criticized as potentially biasing the results towards a three-domains topology but also, when the individual alignments were combined, to have introduced alignment errors between domains ${ }^{19}$. Brown et al. ${ }^{45}$ also inferred trees from a concatenation of a subset of 14 universally conserved proteins, but in this study the tree recovered depended on the phylogenetic method used; the threedomains topology was recovered using maximum parsimony, but model-based methods recovered an eocyte topology.

Over the past few years, phylogenetic models implemented in either a maximum likelihood or Bayesian framework have continued to increase in sophistication by incorporating additional features of the evolutionary process. These include relaxing the assumptions of homogeneous amino acid or base composition across sites ${ }^{46}$ or across branches of the tree ${ }^{31}$. These models appear to fit molecular sequence data much better than simpler models and this may make them less susceptible to LBA and other artifacts of model mis-specification ${ }^{25}$. Although relatively few analyses of the core gene set have used these models so far, all of them have recovered the eocyte tree, rather than the three-domains tree $e^{12,22,47-49}$.

\section{New archaeal lineages and eukaryotic origins}

In addition to improvements in phylogenetic methods, the diversity of molecular sequences from organisms related to the eocytes/Crenarchaeota has also increased dramatically, driven by the ease with which sequences from uncultured prokaryotes can now be sampled from the environment using molecular methods ${ }^{50,51}$. Improved sampling can have positive effects on phylogenetic reconstruction, particularly when 
it helps to break up long branches ${ }^{52}$. Recently discovered relatives of the eocytes/Crenarchaeota include the Korarchaeota ${ }^{53}$, the Thaumarchaeota ${ }^{54}$ and the Aigarchaeota 55 ; the "TACK" superphylum was subsequently proposed as an informal group to encompass these four taxa ${ }^{47}$. To date, the studies including TACK sequences have supported a version of the eocyte hypothesis extended to recognize this improved sampling, rather than the three-domains tree $e^{47,48,56}$. In this extended sense, the eocyte hypothesis implies that the closest relative of the eukaryotic nuclear lineage is one, or all, of the TACK Archaea. If this tree is correct, then an important place to look for prokaryotic homologues of eukaryotic cellular componentry should be among the TACK phyla. Consistent with this prediction, members of this group encode homologues of a number of key eukaryotic genes (Figure 2, Supplementary Table 1), including actin ${ }^{57}$ and tubulin ${ }^{58}$ - the essential components of the eukaryotic cytoskeleton - a ubiquitin protein modification system ${ }^{55}$, and a number of genes involved in transcription and translation ${ }^{47,59}$. However, no single characterized TACK genome possesses all of these features ${ }^{47,57,58}$, implying that gene loss and potentially HGT, have contributed to the patterns of gene sharing on contemporary archaeal and eukaryotic genomes ${ }^{60,61}$.

\section{Which history do universal trees represent?}

In their seminal papers, Woese and Fox ${ }^{1,4}$ recognized that the ribosomal RNA tree represented only one component, the host for the mitochondrial endosymbiont, in the composite origins of the eukaryotic cell. That composite nature has been confirmed by comparative genomics, which has demonstrated that eukaryotic genomes contain a mixture of genes with different origins ${ }^{13,62-66}$. Some genes are ancestrally present in all three groups or unique to eukaryotes, but many others appear to have origins through gene transfers from different bacteria, including the endosymbiotic progenitors of mitochondria and plastids, and relatively few - including the core set of conserved proteins we have been discussing - have affinities with the Archaea. From these data it is clear that no one tree is sufficient to describe the history of all of the genes on modern eukaryotic genomes ${ }^{67,68}$. However, even though this fact is now widely documented, the three domains tree is often still called the "tree of life" or "universal tree" in textbooks ${ }^{15}$ and reviews ${ }^{16,17}$. 
The sequencing of genomes from across the tree of eukaryotes is beginning to provide a clearer picture of the impact on eukaryotic genomes of horizontal gene transfer (HGT) from prokaryotes ${ }^{65}$. These data suggest that the acquisition of bacterial genes, at least by microbial eukaryotes, has been an ongoing process that extends beyond the initial injection of genes provided by the mitochondrial and plastid endosymbionts. From the perspective of ongoing HGT, the existence of any coherent vertical signal for ancient relationships may seem surprising. However, the impact of HGT on the core genes used to reconstruct the tree of life appears rather limited. While cases of HGT have been reported ${ }^{69,70}$, these occur mainly within rather than between domains, and at present there is little evidence that they have generally perturbed inferences of inter-domain relationships ${ }^{3,12,41,69}$. In addition to genuine cases of HGT, poorly-fitting phylogenetic models may also lead to disagreements between gene trees ${ }^{25,26}$ : recent work has shown that improving the fit of phylogenetic models ${ }^{48}$ or integrating the signal from different genes through joint inference of gene and species trees ${ }^{71,72}$ can reduce the level of incongruence and the number of inferred HGT events.

The reasons why core genes involved in transcription, translation and related processes might be transferred (that is, fixed) less frequently than genes for metabolic pathways are currently understood in terms of their degree of functional integration into cells. Their gene products are often found in large sub-cellular complexes and therefore tend to have more interaction partners than genes for metabolic pathways; as a result, horizontal replacement of these genes is more likely to disrupt important cellular interactions and thus to be opposed by negative selection ${ }^{66,73,74}$. In essence, the universal core might be the largest coherent set of vertically inherited genes that can be tracked across the history of cellular life ${ }^{3}$, and as such represents a key resource for tracing the emergence of the eukaryotic cellular lineage. Under the rooted three-domains hypothesis ${ }^{14}$, that ancestral lineage is as old as the Archaea. By contrast, the eocyte hypothesis predicts that eukaryotes are a relatively young group because their core genes originated from within the Archaea ${ }^{18}$.

\section{The origin of eukaryotes in light of other data}

In principle it might be possible to determine the order of events relevant to eukaryotic origins, or at least to exclude some scenarios, using the fossil and 
biogeochemical record. However, this record is very incomplete and subject to deep and sometimes heated controversy. The first fossil that is indisputably eukaryotic is of a bangiophyte red alga dated to between 1.2 billion and 800 million years ago ${ }^{75}$, but earlier microfossils with a possible eukaryotic origin are found in rocks dated to approximately 1.8 billion years ago ${ }^{20}$. These data are consistent with molecular dating analyses that place the last common ancestor of eukaryotes at between 1.9 and 1.7 billion years $\mathrm{ago}^{76}$. An earlier origin for eukaryotes had been suggested based on the presence of sterane biomarkers in 2.7 billion year-old rocks ${ }^{77}$, but these were subsequently shown to be contaminants from younger rocks ${ }^{78,79}$. An early origin for Archaea has been inferred based on the presence of biological methane, today produced only by methanogenic Euryarchaeota, in rocks that are 3.5 billion years old $^{80}$. Analyses of microfossils and stromatolites - modern versions of which harbor complex bacterial communities ${ }^{81}$ - in 3.4 billion year old rocks suggest the presence of photosynthetic bacteria ${ }^{82-84}$. Thus, on the data available, Bacteria and Archaea may pre-date eukaryotes in the fossil record by almost 2 billion years.

In light of the uncertainties for dating eukaryotic origins in the geological record, much attention has focused on the historical record revealed by the ultrastructure of the eukaryotic cell and in particular on the timing of the mitochondrial endosymbiosis ${ }^{85}$. When the three primary kingdoms and three-domains tree were originally proposed $^{1,14}$ some contemporary eukaryotes called 'archezoans ${ }^{95,86}$ were hypothesized to descend from eukaryotic lineages that never had mitochondria ${ }^{85,86}$, providing modern-day evidence for the emergence of nucleated cells before the mitochondrial endosymbiosis. The 'archezoans' included the obligate intracellular parasites Microsporidia and a number of parasitic microaerophilic protists including Entamoeba, Giardia and Trichomonas ${ }^{85,86}$. However, representatives of all of these groups have now been shown to possess a mitochondrial homologue, either a hydrogenosome or mitosome, sharing common ancestry with classical mitochondria ${ }^{2,87}$. These results imply that the mitochondrion was acquired before the radiation of known eukaryotes; therefore, the observation that the mitochondrion descends from an endosymbiotic member of the alphaproteobacteria $^{64,88}$ provides strong evidence that the origin of eukaryotes postdates the origin of that bacterial group ${ }^{2,89}$. A relatively late origin of eukaryotes compared to Bacteria is consistent with the best evidence from the geological record and with 
either the three-domains or eocyte tree rooted on the bacterial stem or within the Bacteria $^{5-11}$. Moreover, if all eukaryotes have both mitochondria and a nucleus, then we can no longer be sure which structure arose first during evolution: in other words, the host cell that acquired the mitochondrion need not have already possessed a nucleus. Indeed, there are now well-argued hypotheses suggesting that the acquisition of the mitochondrion was the key event that sparked the prokaryote to eukaryote transition $^{90,91}$. In any case, the failure of the archezoa hypothesis removes a key obstacle to theories that propose a prokaryotic host for the mitochondrial endosymbiont, including hypotheses that are consistent with the eocyte tree ${ }^{2}$.

\section{The origin of eukaryotic cell membranes}

The plasma membranes of Bacteria and eukaryotes predominantly contain phospholipids in which fatty acids are covalently bound to $s n$-glycerol-3-phosphate via an ester linkage. By contrast, Archaea - including the few TACK Archaea studied so far - predominantly contain phospholipids with isoprenoid chains linked to $s n$-glycerol-1-phosphate via an ether bond ${ }^{92,93}$. This pattern is most parsimoniously explained on the rooted three-domains tree by inferring a switch to using mainly glycerol isoprenoid ethers along the archaeal stem, with eukaryotes retaining the ancestral type. This transition may have been driven by a need to maintain membrane function at the high temperatures and acidic conditions of the habitats occupied by early Archaea ${ }^{92,94}$. A commonly voiced challenge to the eocyte hypothesis - and all Archaea-host models for eukaryotic origins - is how to explain the reversion of the archaeal-host membrane to a bacterial-type plasma membrane.

In fact, most of the genes needed for the synthesis of both types of lipid are common to all three groups, suggesting that neither the transition from ester to ether lipids in the common ancestor of Archaea, nor the subsequent reversion along the eukaryotic stem, would require radical genomic change ${ }^{95,96}$. Archaeal-type ether lipids have been detected in some Bacteria and phospholipids based upon sn-glycerol-1phosphate are found in certain endomembrane components of eukaryotes, suggesting that the distinctions among contemporary membranes may not be as sharp as once thought; there is still much to be discovered about the natural diversity of lipid membranes ${ }^{93,95-98}$. Moreover, recent experiments have indicated that artificial 
membranes containing mixtures of bacterial and archaeal lipids are stable ${ }^{99}$, demonstrating the potential for natural mixed-membrane intermediate stages. Given these considerations, the reversion to bacterial-type membranes in eukaryotes might be explained as part of the same process whereby ancestral archaeal pathways were replaced by bacterial equivalents to yield the metabolic similarities observed between bacteria and contemporary eukaryotes ${ }^{62-65,95,96,100}$. This transition need not have greatly affected membrane function: in the Haloarchaea, which have obtained a large number of bacterial genes by HGT, transporters derived from Bacteria appear to function normally in the archaeal plasma membrane ${ }^{101}$.

\section{Conclusions}

Ancient phylogenies provide a fascinating window into the distant past, but are difficult to build and interpret - as evidenced by the first thirty years of debate over the tree of life in the era of molecular phylogenetics. Evolutionary biologists now have access to more data and better phylogenetic methods than ever before, although there is still much room for improvement and many uncertainties remain. These caveats apply equally to all attempts to infer ancient relationships, affecting not only the debate over whether the three-domains or eocyte tree best depicts the history of core eukaryotic genes, but also the placement of the universal $\operatorname{root}^{5,9-12,21}$ and the relationships between major eukaryotic phyla ${ }^{26,102,103}$. The pioneering analyses of molecular sequence data led by Carl Woese and his co-workers culminated in the three-domains tree recognizing the Archaea, Bacteria and Eukaryota as the three primary domains of cellular life. While evidence of widespread horizontal gene transfer means that no single tree can depict the history of all genes on prokaryotic and eukaryotic genomes, the three domains tree holds a special place in biology. It appears in most textbooks and reviews, where it is often called the "universal tree" and the "tree of life". But support for the iconic three-domains tree has waned with improvements in phylogenetic methods and taxon sampling. Within the limits of methods and data, a version of the eocyte tree is now the best-supported hypothesis for the origin of the subset of genes that mainly function in translation and appear to be most resistant to horizontal gene transfer. The placement of these genes, and by extension the eukaryotic nuclear lineage, within the Archaea is consistent with only two primary lineages and with hypotheses for a symbiogenetic origin for eukaryotes 
involving an archaeon and one or more bacterial partners. The eocyte tree, if correct, suggests that the TACK Archaea, currently a relatively unexplored group, might contain additional clues as to the origin of complex eukaryotic structures. It also rejects the hypothesis that eukaryotes are a primordial cellular lineage, leaving only two candidate primary domains, Archaea and Bacteria, and it identifies a key piece of the puzzle - the host lineage - in the chimeric origins of the eukaryotic cell.

\section{Figure legends}

Figure 1: Competing hypotheses for the origin of the eukaryotic host cell. (a) The rooted three-domains tree ${ }^{14}$ depicts cellular life divided into three major monophyletic groups or domains; the Bacteria, Archaea, and the Eukaryota - the latter representing the host lineage, sometimes also called the nuclear or nucleo-cytoplasmic lineage ${ }^{5}$, that acquired the mitochondrial endosymbiont. In this tree the Archaea and Eukaryota are most closely related to each other because they share a common ancestor that is not shared with Bacteria. (b) The rooted eocyte tree recovers the host cell lineage nested within the Archaea as a sister group to the eocytes (which Woese et al. ${ }^{14}$ called the Crenarchaeota); this implies that, based upon the small set of core genes, there are only two primary domains of life - the Bacteria and Archaea. In its modern formulation shown here the eocyte hypothesis implies that the closest relative of the eukaryotic nuclear lineage is one, or all, of the TACK Archaea, which include newly discovered relatives of the eocytes/Crenarchaeota. Both trees have been traditionally rooted on the bacterial stem consistent with some published analyses ${ }^{5-8}$.

\section{Figure 2: Archaeal links in the origin of eukaryotes.}

A schematic tree depicting the relationships between Archaea and the eukaryotic nuclear lineage consistent with recent analyses of core genes using new methods ${ }^{47-49}$ and rooted using the bacteria as the outgroup ${ }^{5-11}$. The phylogenetic position of Korarchaeum was not consistently resolved in these different analyses and hence is depicted as part of a polytomy. Genome analyses have detected homologous genes in Archaea and eukaryotes that are consistent with them sharing a common ancestor to the exclusion of Bacteria. Many of these patterns of gene sharing do not distinguish 
between the rooted three domains or eocyte trees, as they are expected to occur under both hypotheses. Recently published analyses of the genomes of TACK Archaea, however, have increased the number of homologues shared with eukaryotes and some of these are relevant to ideas about eukaryotic origins and the evolution of their unique features. These include putative orthologues of $\operatorname{actin}^{57}$ and tubulin ${ }^{58}$, which in eukaryotes form the core of the cytoskeleton, as well as components of a ubiquitin protein modification system in Caldiarchaeum subterraneum ${ }^{55}$. Distant homologues of some of these genes have also been detected in Euryarchaeota ${ }^{104,105}$, but they cluster outside the eukaryote/TACK clade in phylogenetic trees ${ }^{57,58,106}$. We have followed existing usage ${ }^{58}$ in distinguishing between the FtsZ-like tubulin family members found in some Archaea and the eukaryote-like tubulin homologue found in Nitrosoarchaeum. Several eukaryotic genes involved in transcription and translation have prokaryotic homologues or conserved sequence features that have been found so far only among the TACK Archaea. These include four ribosomal proteins ${ }^{47}$, the RNA polymerase subunit $\mathrm{RpoG}^{59}$, the elongation factor Elf $1^{107}$, and a short amino acid insertion ${ }^{108}$ in the broadly-conserved elongation factor 1-alpha that has only been found in TACK Archaea and eukaryotes as indicated by the vertical bar. Accession numbers and additional details are provided in Supplementary Tables 1 and 2.

\section{Acknowledgements}

This work was supported by a Marie Curie postdoctoral fellowship to T.A.W. T.M.E. acknowledges support from the European Research Council Advanced Investigator Programme and the Wellcome Trust. We thank John Archibald for critical comments on the manuscript.

\section{References}

1 Woese, C. R. \& Fox, G. E. Phylogenetic structure of the prokaryotic domain: the primary kingdoms. Proc Natl Acad Sci U S A 74, 5088-5090 (1977).

\section{A landmark paper that together with [4] reported the discovery of the Archaea and discussed its far-reaching implications for early evolution.}


2 Embley, T. M. \& Martin, W. Eukaryotic evolution, changes and challenges. Nature 440, 623-630 (2006).

3 Woese, C. R. On the evolution of cells. Proc Natl Acad Sci U S A 99, 87428747 (2002).

4 Woese, C. R. \& Fox, G. E. The concept of cellular evolution. J Mol Evol 10, 16 (1977).

5 Doolittle, W. F. \& Brown, J. R. Tempo, mode, the progenote, and the universal root. Proc Natl Acad Sci U S A 91, 6721-6728 (1994).

6 Iwabe, N., Kuma, K., Hasegawa, M., Osawa, S. \& Miyata, T. Evolutionary relationship of archaebacteria, eubacteria, and eukaryotes inferred from phylogenetic trees of duplicated genes. Proc Natl Acad Sci U S A 86, 93559359 (1989).

Together with [7], this paper presented the first evidence for rooting the tree of life on the bacterial stem but see [5] for a still relevant discussion of these analyses and other contemporary ideas about early evolution.

7 Gogarten, J. P. et al. Evolution of the vacuolar H+-ATPase: implications for the origin of eukaryotes. Proc Natl Acad Sci U S A 86, 6661-6665 (1989).

8 Dagan, T., Roettger, M., Bryant, D. \& Martin, W. Genome networks root the tree of life between prokaryotic domains. Genome Biol Evol 2, 379-392 (2010).

9 Lake, J. A., Skophammer, R. G., Herbold, C. W. \& Servin, J. A. Genome beginnings: rooting the tree of life. Phil Trans R Soc B 364, 2177-2185 (2009).

10 Skophammer, R. G., Servin, J. A., Herbold, C. W. \& Lake, J. A. Evidence for a gram-positive, eubacterial root of the tree of life. Mol Biol Evol 24, 17611768 (2007).

11 Cavalier-Smith, T. Rooting the tree of life by transition analyses. Biol Direct 1, 19 (2006).

12 Cox, C. J., Foster, P. G., Hirt, R. P., Harris, S. R. \& Embley, T. M. The archaebacterial origin of eukaryotes. Proc Natl Acad Sci U S A 105, 2035620361 (2008).

The first of a series of recent papers demonstrating that analyses of core genes using new phylogenetic models favor the eocyte tree rather than the threedomains tree.

13 Doolittle, W. F., Zhaxybayeva, O. in The Prokaryotes: Prokaryotic Biology and Symbiotic Associations (ed E. Rosenberg) (Springer, 2013).

A very clear discussion about the issues facing the integration of phylogenetics and classification given the evidence for extensive lateral gene transfer.

14 Woese, C. R., Kandler, O. \& Wheelis, M. L. Towards a natural system of organisms: proposal for the domains Archaea, Bacteria, and Eucarya. Proc Natl Acad Sci U S A 87, 4576-4579 (1990). 
Woese and colleagues present their arguments for the rooted three-domains tree of life.

15 Madigan, M. T. M., J.M.; Stahl, D.A.; Clark, D. P. Brock Biology of Microorganisms. 13 edn, (Benjamin Cummings, 2010).

16 Pace, N. R. Time for a change. Nature 441, 289 (2006).

17 Pace, N. R. Mapping the tree of life: progress and prospects. Microbiol Mol Biol Rev 73, 565-576 (2009).

18 Lake, J. A., Henderson, E., Oakes, M. \& Clark, M. W. Eocytes: a new ribosome structure indicates a kingdom with a close relationship to eukaryotes. Proc Natl Acad Sci U S A 81, 3786-3790 (1984).

This paper presents comparisons of ribosomal structure in Bacteria, Archaea and eukaryotes, providing the initial motivation for the eocyte hypothesis.

19 Gribaldo, S., Poole, A. M., Daubin, V., Forterre, P. \& Brochier-Armanet, C. The origin of eukaryotes and their relationship with the Archaea: are we at a phylogenomic impasse? Nat Rev Microbiol 8, 743-752 (2010).

20 Knoll, A. H., Javaux, E. J., Hewitt, D. \& Cohen, P. Eukaryotic organisms in Proterozoic oceans. Phil Trans R Soc B 361, 1023-1038 (2006).

21 Philippe, H. \& Forterre, P. The rooting of the universal tree of life is not reliable. J Mol Evol 49, 509-523 (1999).

22 Foster, P. G., Cox, C. J. \& Embley, T. M. The primary divisions of life: a phylogenomic approach employing composition-heterogeneous methods. Phil Trans R Soc B 364, 2197-2207 (2009).

23 Penny, D., McComish, B. J., Charleston, M. A. \& Hendy, M. D. Mathematical elegance with biochemical realism: the covarion model of molecular evolution. J Mol Evol 53, 711-723 (2001).

24 Ho, S. Y. \& Jermiin, L. Tracing the decay of the historical signal in biological sequence data. Syst Biol 53, 623-637 (2004).

25 Lartillot, N., Brinkmann, H. \& Philippe, H. Suppression of long-branch attraction artefacts in the animal phylogeny using a site-heterogeneous model. BMC Evol Biol 7 Suppl 1, S4 (2007).

26 Philippe, H. et al. Resolving difficult phylogenetic questions: Why more sequences are not enough. PLoS Biol 9, e1000602 (2011).

27 Gouy, M. \& Li, W. H. Phylogenetic analysis based on rRNA sequences supports the archaebacterial rather than the eocyte tree. Nature 339, 145-147 (1989).

28 Woese, C. R. Bacterial evolution. Microbiol Rev 51, 221-271 (1987).

29 Olsen, G. J. Earliest phylogenetic branchings: comparing rRNA-based evolutionary trees inferred with various techniques. Cold Spring Harbor symposia on quantitative biology 52, 825-837 (1987).

30 Foster, P. G. \& Hickey, D. A. Compositional bias may affect both DNA-based and protein-based phylogenetic reconstructions. J Mol Evol 48, 284-290 (1999).

31 Foster, P. G. Modeling compositional heterogeneity. Syst Biol 53, 485-495 (2004). 
32 Hirt, R. P. et al. Microsporidia are related to Fungi: evidence from the largest subunit of RNA polymerase II and other proteins. Proc Natl Acad Sci U S A 96, 580-585 (1999).

33 Lake, J. A. Reconstructing evolutionary trees from DNA and protein sequences: paralinear distances. Proc Natl Acad Sci U S A 91, 1455-1459 (1994).

34 Yang, Z. \& Roberts, D. On the use of nucleic acid sequences to infer early branchings in the tree of life. Mol Biol Evol 12, 451-458 (1995).

An important early contribution demonstrating that modeling changing nucleotide composition in RNA sequences from different species supported the eocyte tree.

35 Felsenstein, J. Cases in which parsimony or compatibility methods will be positively misleading. Syst Zool 27, 401-410 (1978).

36 Yang, Z. \& Rannala, B. Molecular phylogenetics: principles and practice. Nat Rev Genet 13, 303-314 (2012).

37 Lake, J. A. Origin of the eukaryotic nucleus determined by rate-invariant analysis of rRNA sequences. Nature 331, 184-186 (1988).

38 Sidow, A. \& Wilson, A. C. Compositional statistics: an improvement of evolutionary parsimony and its application to deep branches in the tree of life. J Mol Evol 31, 51-68 (1990).

39 Tourasse, N. J. \& Gouy, M. Accounting for evolutionary rate variation among sequence sites consistently changes universal phylogenies deduced from rRNA and protein-coding genes. Mol Phylogenet Evol 13, 159-168 (1999).

40 Yutin, N., Makarova, K. S., Mekhedov, S. L., Wolf, Y. I. \& Koonin, E. V. The deep archaeal roots of eukaryotes. Mol Biol Evol 25, 1619-1630 (2008).

41 Harris, J. K., Kelley, S. T., Spiegelman, G. B. \& Pace, N. R. The genetic core of the universal ancestor. Genome Res 13, 407-412 (2003).

42 Katoh, K., Kuma, K. \& Miyata, T. Genetic algorithm-based maximumlikelihood analysis for molecular phylogeny. J Mol Evol 53, 477-484 (2001).

43 Ciccarelli, F. D. et al. Toward automatic reconstruction of a highly resolved tree of life. Science 311, 1283-1287 (2006).

44 Lake, J. A. The order of sequence alignment can bias the selection of tree topology. Mol Biol Evol 8, 378-385 (1991).

45 Brown, J. R., Douady, C. J., Italia, M. J., Marshall, W. E. \& Stanhope, M. J. Universal trees based on large combined protein sequence data sets. Nat Genet 28, 281-285 (2001).

46 Lartillot, N. \& Philippe, H. A Bayesian mixture model for across-site heterogeneities in the amino-acid replacement process. Mol Biol Evol 21, 1095-1109 (2004).

One of the most significant improvements in phylogenetic modeling in the last decade, providing a Bayesian framework for accommodating across-site compositional heterogeneity - a key feature of molecular sequence data. 
47 Guy, L. \& Ettema, T. J. The archaeal 'TACK' superphylum and the origin of eukaryotes. Trends Microbiol 19, 580-587 (2011).

48 Williams, T. A., Foster, P. G., Nye, T. M., Cox, C. J. \& Embley, T. M. A congruent phylogenomic signal places eukaryotes within the Archaea. Proc R Soc B 279, 4870-4879 (2012).

49 Lasek-Nesselquist, E. \& Gogarten, J. P. The effects of model choice and mitigating bias on the ribosomal tree of life. Mol Phylogenet Evol 69, 1738 (2013).

50 Pester, M., Schleper, C. \& Wagner, M. The Thaumarchaeota: an emerging view of their phylogeny and ecophysiology. Curr Opin Microbiol 14, 300306 (2011).

51 Lloyd, K. G. et al. Predominant archaea in marine sediments degrade detrital proteins. Nature 496, 215-218 (2013).

52 Graybeal, A. Is it better to add taxa or characters to a difficult phylogenetic problem? Syst Biol 47, 9-17 (1998).

53 Elkins, J. G. et al. A korarchaeal genome reveals insights into the evolution of the Archaea. Proc Natl Acad Sci U S A 105, 8102-8107 (2008).

54 Brochier-Armanet, C., Boussau, B., Gribaldo, S. \& Forterre, P. Mesophilic Crenarchaeota: proposal for a third archaeal phylum, the Thaumarchaeota. Nat Rev Microbiol 6, 245-252 (2008).

55 Nunoura, T. et al. Insights into the evolution of Archaea and eukaryotic protein modifier systems revealed by the genome of a novel archaeal group. Nucleic Acids Res 39, 3204-3223 (2011).

56 Kelly, S., Wickstead, B. \& Gull, K. Archaeal phylogenomics provides evidence in support of a methanogenic origin of the Archaea and a thaumarchaeal origin for the eukaryotes. Proc R Soc B 278, 1009-1018 (2011).

57 Ettema, T. J., Lindas, A. C. \& Bernander, R. An actin-based cytoskeleton in archaea. Mol Microbiol 80, 1052-1061 (2011).

58 Yutin, N. \& Koonin, E. V. Archaeal origin of tubulin. Biol Direct 7, 10 (2012).

59 Koonin, E. V., Makarova, K. S. \& Elkins, J. G. Orthologs of the small RPB8 subunit of the eukaryotic RNA polymerases are conserved in hyperthermophilic Crenarchaeota and "Korarchaeota". Biol Direct 2, 38 (2007).

60 Csuros, M. \& Miklos, I. Streamlining and large ancestral genomes in Archaea inferred with a phylogenetic birth-and-death model. Mol Biol Evol 26, 2087-2095 (2009).

61 Wolf, Y. I., Makarova, K. S., Yutin, N. \& Koonin, E. V. Updated clusters of orthologous genes for Archaea: a complex ancestor of the Archaea and the byways of horizontal gene transfer. Biol Direct 7, 46 (2012).

62 Ribeiro, S. \& Golding, G. B. The mosaic nature of the eukaryotic nucleus. Mol Biol Evol 15, 779-788 (1998).

Together with [63], this paper presented some of the first evidence based upon trees that eukaryotes are genomic chimeras containing some genes that are most similar to those of Bacteria and others to Archaea. 
63 Rivera, M. C., Jain, R., Moore, J. E. \& Lake, J. A. Genomic evidence for two functionally distinct gene classes. Proc Natl Acad Sci U S A 95, 6239-6244 (1998).

64 Esser, C. et al. A genome phylogeny for mitochondria among alphaproteobacteria and a predominantly eubacterial ancestry of yeast nuclear genes. Mol Biol Evol 21, 1643-1660 (2004).

65 Alsmark, U. C. et al. Patterns of prokaryotic lateral gene transfers affecting parasitic microbial eukaryotes. Genome Biol R14:19 (2013).

66 Cotton, J. A. \& McInerney, J. O. Eukaryotic genes of archaebacterial origin are more important than the more numerous eubacterial genes, irrespective of function. Proc Natl Acad Sci U S A 107, 17252-17255 (2010).

67 Dagan, T. \& Martin, W. The tree of one percent. Genome Biol 7, 118 (2006).

68 Doolittle, W. F. \& Bapteste, E. Pattern pluralism and the Tree of Life hypothesis. Proc Natl Acad Sci U S A 104, 2043-2049 (2007).

69 Williams, D., et al. A rooted net of life. Biol Direct 6, 45 (2011).

70 Creevey, C. J., Doerks, T., Fitzpatrick, D. A., Raes, J. \& Bork, P. Universally distributed single-copy genes indicate a constant rate of horizontal transfer. PLoS One 6, e22099 (2011).

71 Boussau, B. et al. Genome-scale coestimation of species and gene trees. Genome Res 23, 323-330 (2013).

72 Szollosi, G. J., Boussau, B., Abby, S. S., Tannier, E. \& Daubin, V. Phylogenetic modeling of lateral gene transfer reconstructs the pattern and relative timing of speciations. Proc Natl Acad Sci U S A 109, 17513-17518 (2012).

73 Cohen, O., Gophna, U. \& Pupko, T. The complexity hypothesis revisited: connectivity rather than function constitutes a barrier to horizontal gene transfer. Mol Biol Evol 28, 1481-1489 (2011).

74 Jain, R., Rivera, M. C. \& Lake, J. A. Horizontal gene transfer among genomes: the complexity hypothesis. Proc Natl Acad Sci U S A 96, 38013806 (1999).

75 Butterfield, N. J. Bangiomorpha pubescens n. gen., n. sp.: implications for the evolution of sex, multicellularity, and the Mesoproterozoic/Neoproterozoic radiation of eukaryotes. Paleobiology 26, 386-404 (2000).

76 Parfrey, L. W., Lahr, D. J., Knoll, A. H. \& Katz, L. A. Estimating the timing of early eukaryotic diversification with multigene molecular clocks. Proc Natl Acad Sci U S A 108, 13624-13629 (2011).

77 Brocks, J. J., Logan, G. A., Buick, R. \& Summons, R. E. Archean molecular fossils and the early rise of eukaryotes. Science 285, 1033-1036 (1999).

78 Rasmussen, B., Fletcher, I. R., Brocks, J. J. \& Kilburn, M. R. Reassessing the first appearance of eukaryotes and cyanobacteria. Nature 455, 1101-1104 (2008).

79 Fischer, W. W. Biogeochemistry: Life before the rise of oxygen. Nature 455, 1051-1052 (2008).

80 Ueno, Y., Yamada, K., Yoshida, N., Maruyama, S. \& Isozaki, Y. Evidence from fluid inclusions for microbial methanogenesis in the early Archaean era. Nature 440, 516-519 (2006).

81 Papineau, D., Walker, J. J., Mojzsis, S. J. \& Pace, N. R. Composition and structure of microbial communities from stromatolites of Hamelin Pool in 
Shark Bay, Western Australia. Appl Environ Microbiol 71, 4822-4832 (2005).

82 Allwood, A. C. et al. Controls on development and diversity of Early Archean stromatolites. Proc Natl Acad Sci U S A 106, 9548-9555 (2009).

83 Tice, M. M. \& Lowe, D. R. Photosynthetic microbial mats in the 3,416-Myrold ocean. Nature 431, 549-552 (2004).

84 Schopf, J. W. Fossil evidence of Archaean life. Phil Trans R Soc B 361, 869885 (2006).

85 Cavalier-Smith, T. Eukaryotes with no mitochondria. Nature 326, 332-333 (1987).

86 Cavalier-Smith, T. in Endocytobiology II (ed W. Schwemmler, Schenk H.E.A.) 1027-1034 (de Gruyter, 1983).

87 Van der Giezen, M., Tovar, J. \& Clark, C. G. Mitochondria-derived organelles in protists and fungi. Int Rev Cytol 244, 175-225 (2005).

88 Andersson, S. G. et al. The genome sequence of Rickettsia prowazekii and the origin of mitochondria. Nature 396, 133-140 (1998).

89 Horner, D. S., Hirt, R. P., Kilvington, S., Lloyd, D. \& Embley, T. M. Molecular data suggest an early acquisition of the mitochondrion endosymbiont. Proc R Soc B 263, 1053-1059 (1996).

90 Lane, N. \& Martin, W. The energetics of genome complexity. Nature 467, 929-934 (2010).

91 Martin, W. \& Koonin, E. V. Introns and the origin of nucleus-cytosol compartmentalization. Nature 440, 41-45 (2006).

92 Lombard, J., Lopez-Garcia, P. \& Moreira, D. The early evolution of lipid membranes and the three domains of life. Nat Rev Microbiol 10, 507-515 (2012).

93 Pitcher, A. et al. Core and intact polar glycerol dibiphytanyl glycerol tetraether lipids of ammonia-oxidizing archaea enriched from marine and estuarine sediments. Appl Environ Microbiol 77, 3468-3477 (2011).

94 van de Vossenberg, J. L., Driessen, A. J. \& Konings, W. N. The essence of being extremophilic: the role of the unique archaeal membrane lipids. Extremophiles 2, 163-170 (1998).

95 Boucher, Y., Kamekura, M. \& Doolittle, W. F. Origins and evolution of isoprenoid lipid biosynthesis in archaea. Mol Microbiol 52, 515-527 (2004).

96 Lombard, J., Lopez-Garcia, P. \& Moreira, D. An ACP-independent fatty acid synthesis pathway in archaea: implications for the origin of phospholipids. Mol Biol Evol 29, 3261-3265 (2012).

97 Guldan, H., Matysik, F. M., Bocola, M., Sterner, R. \& Babinger, P. Functional assignment of an enzyme that catalyzes the synthesis of an archaea-type ether lipid in bacteria. Angew Chem Int Ed Engl 50, 8188-8191 (2011).

98 Tan, H. H., Makino, A., Sudesh, K., Greimel, P. \& Kobayashi, T. Spectroscopic evidence for the unusual stereochemical configuration of an endosome-specific lipid. Angew Chem Int Ed Engl 51, 533-535 (2012).

99 Shimada, H. \& Yamagishi, A. Stability of heterochiral hybrid membrane made of bacterial sn-G3P lipids and archaeal sn-G1P lipids. Biochemistry 50, 4114-4120 (2011). 
Reports the production of stable heterochiral membranes containing a mixture of bacterial- and archaeal-type lipids demonstrating the feasibility of natural mixed membranes.

100 Martin, W. \& Muller, M. The hydrogen hypothesis for the first eukaryote. Nature 392, 37-41 (1998).

101 Nelson-Sathi, S. et al. Acquisition of 1,000 eubacterial genes physiologically transformed a methanogen at the origin of Haloarchaea. Proc Natl Acad Sci U S A 109, 20537-20542 (2012).

102 Hampl, V. et al. Phylogenomic analyses support the monophyly of Excavata and resolve relationships among eukaryotic "supergroups". Proc Natl Acad Sci U S A 106, 3859-3864 (2009).

103 Song, S., Liu, L., Edwards, S. V. \& Wu, S. Resolving conflict in eutherian mammal phylogeny using phylogenomics and the multispecies coalescent model. Proc Natl Acad Sci U S A 109, 14942-14947 (2012).

104 Lindas, A. C., Karlsson, E. A., Lindgren, M. T., Ettema, T. J. \& Bernander, R. A unique cell division machinery in the Archaea. Proc Natl Acad Sci U S A 105, 18942-18946 (2008).

105 Makarova, K. S., Yutin, N., Bell, S. D. \& Koonin, E. V. Evolution of diverse cell division and vesicle formation systems in Archaea. Nat Rev Microbiol 8, 731-741 (2010).

106 Blombach, F. et al. Identification of an ortholog of the eukaryotic RNA polymerase III subunit RPC34 in Crenarchaeota and Thaumarchaeota suggests specialization of RNA polymerases for coding and non-coding RNAs in Archaea. Biol Direct 4, 39 (2009).

107 Daniels, J. P., Kelly, S., Wickstead, B. \& Gull, K. Identification of a crenarchaeal orthologue of Elf1: implications for chromatin and transcription in Archaea. Biol Direct 4, 24 (2009).

108 Rivera, M. C. \& Lake, J. A. Evidence that eukaryotes and eocyte prokaryotes are immediate relatives. Science 257, 74-76 (1992). 


\section{Supplementary Table 1: Gene presence and absence data presented in Figure 2 of the main text.}

When considering patterns of gene sharing between eukaryotes and the Archaea, at least three classes of genes are evident. The first comprises cases in which orthologues of the eukaryotic gene are conserved across the Archaea, and sometimes also in Bacteria; these include among their number the core gene set used in analyses upon which the tree in Figure 2 is based. The second class includes eukaryotic genes such as actin $^{1}$, tubulin ${ }^{2}$ and proteins of the ubiquitin modification system ${ }^{3}$. These genes may form large gene families, for example the tubulin/FtsZ gene family, and may have detectable dispersed paralogues among prokaryotes generally, but for which putative orthologues ${ }^{2}$ to eukaryotic versions have so far been detected only among the TACK Archaea. The third class includes genes that have so far been found only in eukaryotes and the TACK Archaea; these include several genes involved in transcription and translation, as detailed below.

\begin{tabular}{|c|c|c|c|c|}
\hline Gene & $\begin{array}{l}\text { Representative } \\
\text { archaeal species }\end{array}$ & $\begin{array}{l}\text { NCBI } \\
\text { Accession } \\
\text { (GI) } \\
\end{array}$ & Reference & $\begin{array}{l}\text { Basis for } \\
\text { orthology } \\
\text { inference }\end{array}$ \\
\hline $\begin{array}{l}\text { Actin } \\
\text { (Crenactin) }\end{array}$ & Thermofilum pendens & 119719444 & 1 & Tree \\
\hline $\begin{array}{l}\text { Tubulin } \\
\text { (artubulin) }\end{array}$ & Nitrosoarchaeum limnia & 494643832 & 2 & Tree \\
\hline $\begin{array}{l}\text { Ubiquitin } \\
\text { system (Ub, } \\
\text { E1, E2, } \\
\text { RING-finger } \\
\text { containing Ub } \\
\text { ligase) }\end{array}$ & $\begin{array}{l}\text { Caldiarchaeum } \\
\text { subterraneum }\end{array}$ & $\begin{array}{l}343485671, \\
343485673, \\
343485672, \\
343485674\end{array}$ & 3 & $\begin{array}{l}\text { Sequence } \\
\text { similarity, } \\
\text { operon } \\
\text { structure }\end{array}$ \\
\hline $\begin{array}{l}\text { Elongation } \\
\text { factor Elf1 }\end{array}$ & Sulfolobus solfataricus & 13813400 & 4,5 & $\begin{array}{l}\text { Not } \\
\text { detected } \\
\text { outside } \\
\text { group }\end{array}$ \\
\hline $\begin{array}{l}\text { RNA } \\
\text { polymerase } \\
\text { RpoG/Rpb8 }\end{array}$ & Thermofilum pendens & 119719267 & 6 & $\begin{array}{l}\text { Not } \\
\text { detected } \\
\text { outside } \\
\text { group }\end{array}$ \\
\hline $\begin{array}{l}\text { Ribosomal } \\
\text { protein } \mathrm{S} 25 \mathrm{e}\end{array}$ & Thermofilum pendens & 119719924 & 4 & $\begin{array}{l}\text { Not } \\
\text { detected } \\
\text { outside } \\
\text { group }\end{array}$ \\
\hline $\begin{array}{l}\text { Ribosomal } \\
\text { protein } \mathrm{S} 30 \mathrm{e}\end{array}$ & Thermofilum pendens & 119719279 & 4 & $\begin{array}{l}\text { Not } \\
\text { detected } \\
\text { outside } \\
\text { group }\end{array}$ \\
\hline $\begin{array}{l}\text { Ribosomal } \\
\text { protein L13e }\end{array}$ & Thermofilum pendens & 119719644 & 4 & $\begin{array}{l}\text { Not } \\
\text { detected } \\
\text { outside } \\
\text { group }\end{array}$ \\
\hline $\begin{array}{l}\text { Ribosomal } \\
\text { protein L38e }\end{array}$ & Aeropyrum pernix & 499163706 & 4 & $\begin{array}{l}\text { Not } \\
\text { detected }\end{array}$ \\
\hline
\end{tabular}




\begin{tabular}{|l|l|l|l|l|}
\hline & & & & $\begin{array}{l}\text { outside } \\
\text { group }\end{array}$ \\
\hline
\end{tabular}

Supplementary Table 2: An amino acid insertion in the elongation factor 1-alpha genes of eukaryotes and certain Archaea. An insertion ${ }^{7}$ is present in the Thaumarchaeota, Aigarchaeota and Crenarchaeota highlighted in Figure 2; this insertion is apparently missing from Korarchaeum cryptophilum. The coordinates provided refer to the portion of the insertion that is readily alignable among the compared sequences.

\begin{tabular}{|l|l|l|}
\hline Species & $\begin{array}{l}\text { Elongation factor } \\
\text { 1-alpha accession }\end{array}$ & $\begin{array}{l}\text { Amino acid } \\
\text { coordinates }\end{array}$ \\
\hline Caldiarchaeum subterraneum & 315425766 & $120-127$ \\
\hline Cenarchaeum symbiosum & 118575602 & $125-132$ \\
\hline Nitrosopumilus maritimus & 161528542 & $121-128$ \\
\hline Nitrosoarchaeum limnia & 494643908 & $121-129$ \\
\hline Thermofilum pendens & 119719557 & $121-128$ \\
\hline Pyrobaculum aerophilum & 18313751 & $131-138$ \\
\hline Caldivirga maquilingensis & 159042306 & $130-137$ \\
\hline Sulfolobus solfataricus & & $120-127$ \\
\hline Ignicoccus hospitalis & 15897164 & $122-129$ \\
\hline Staphylothermus marinus & & $121-128$ \\
\hline Aeropyrum pernix & 156937938 & \\
\hline & & 1260127 \\
\hline
\end{tabular}

1 Ettema, T. J., Lindas, A. C. \& Bernander, R. An actin-based cytoskeleton in archaea. Mol Microbiol 80, 1052-1061 (2011).

2 Yutin, N. \& Koonin, E. V. Archaeal origin of tubulin. Biol Direct 7, 10 (2012).

3 Nunoura, T. et al. Insights into the evolution of Archaea and eukaryotic protein modifier systems revealed by the genome of a novel archaeal group. Nucleic Acids Res 39, 3204-3223 (2011). 
4 Guy, L. \& Ettema, T. J. The archaeal 'TACK' superphylum and the origin of eukaryotes. Trends Microbiol 19, 580-587 (2011).

5 Daniels, J. P., Kelly, S., Wickstead, B. \& Gull, K. Identification of a crenarchaeal orthologue of Elf1: implications for chromatin and transcription in Archaea. Biol Direct 4, 24 (2009).

6 Koonin, E. V., Makarova, K. S. \& Elkins, J. G. Orthologs of the small RPB8 subunit of the eukaryotic RNA polymerases are conserved in hyperthermophilic Crenarchaeota and "Korarchaeota". Biol Direct 2, 38 (2007).

7 Rivera, M. C. \& Lake, J. A. Evidence that eukaryotes and eocyte prokaryotes are immediate relatives. Science 257, 74-76 (1992). 


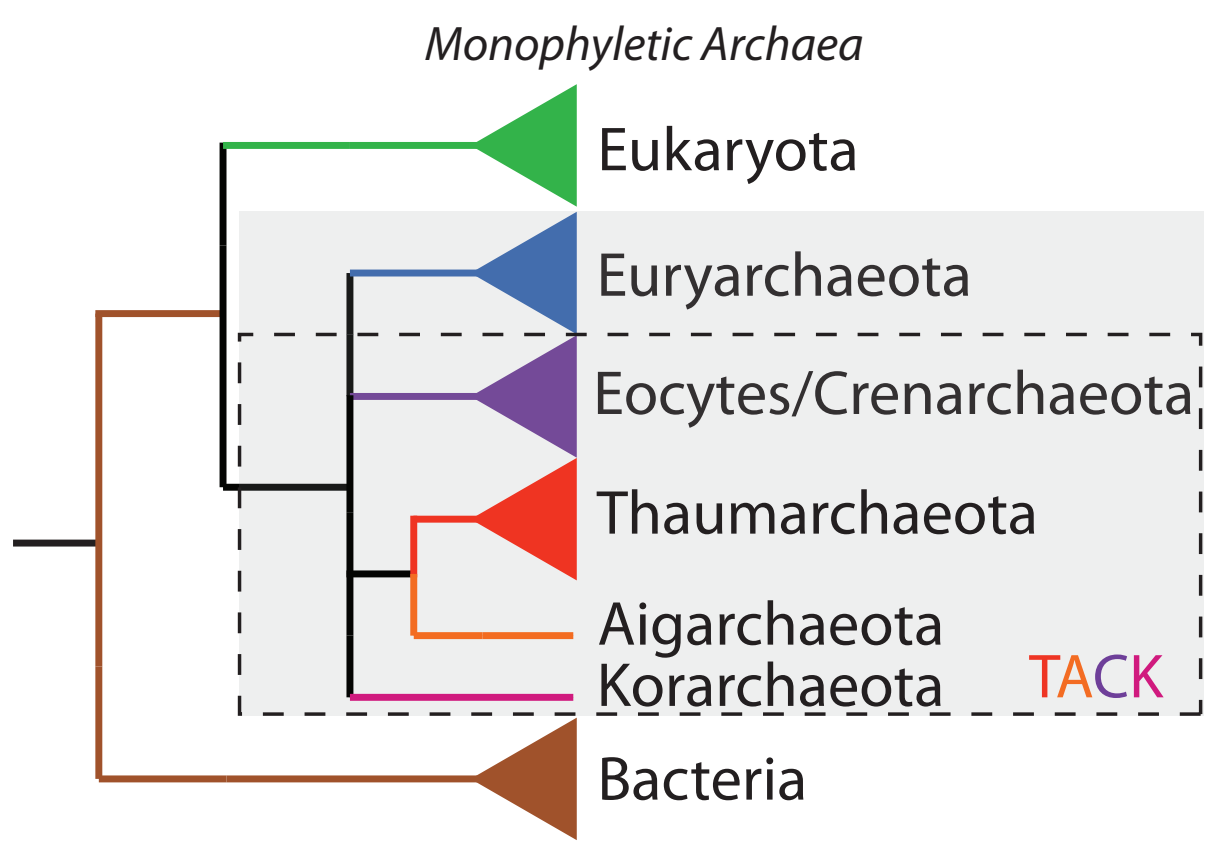

(a) Three domains hypothesis

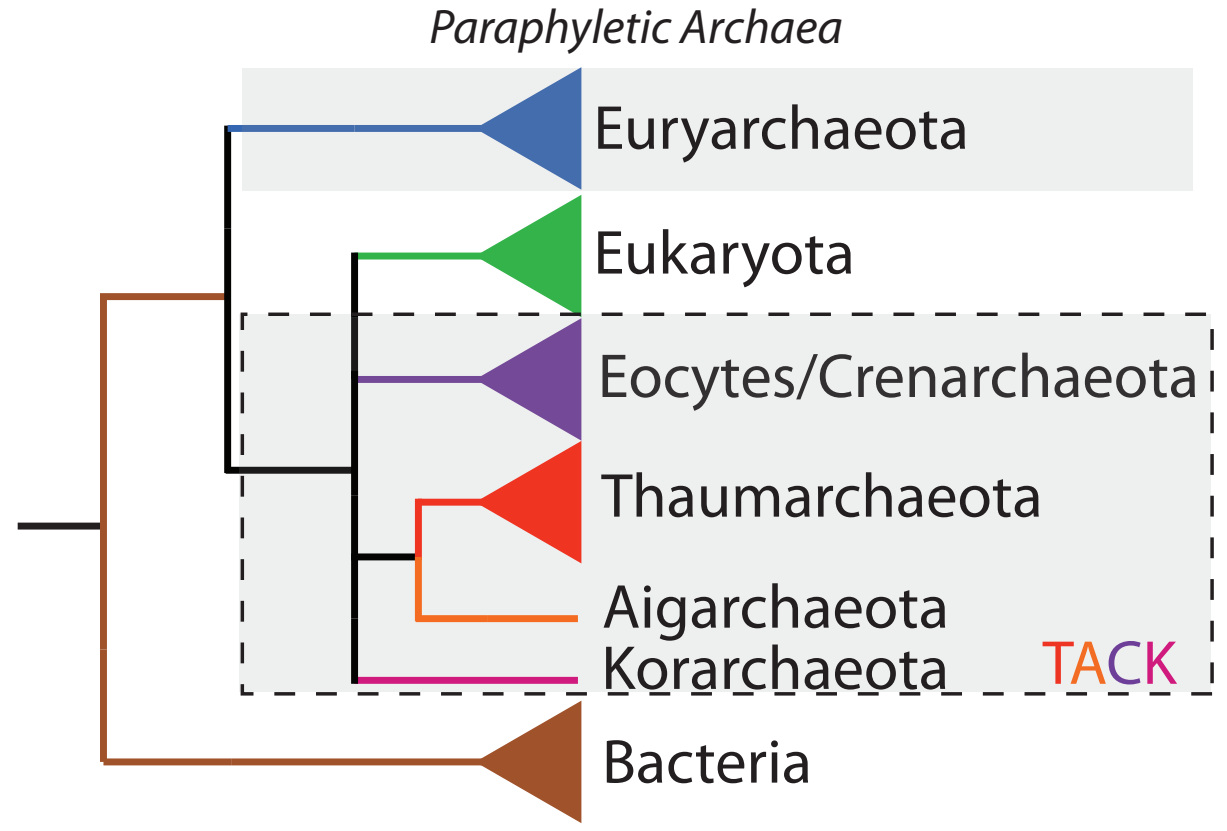

(b) Eocyte hypothesis 


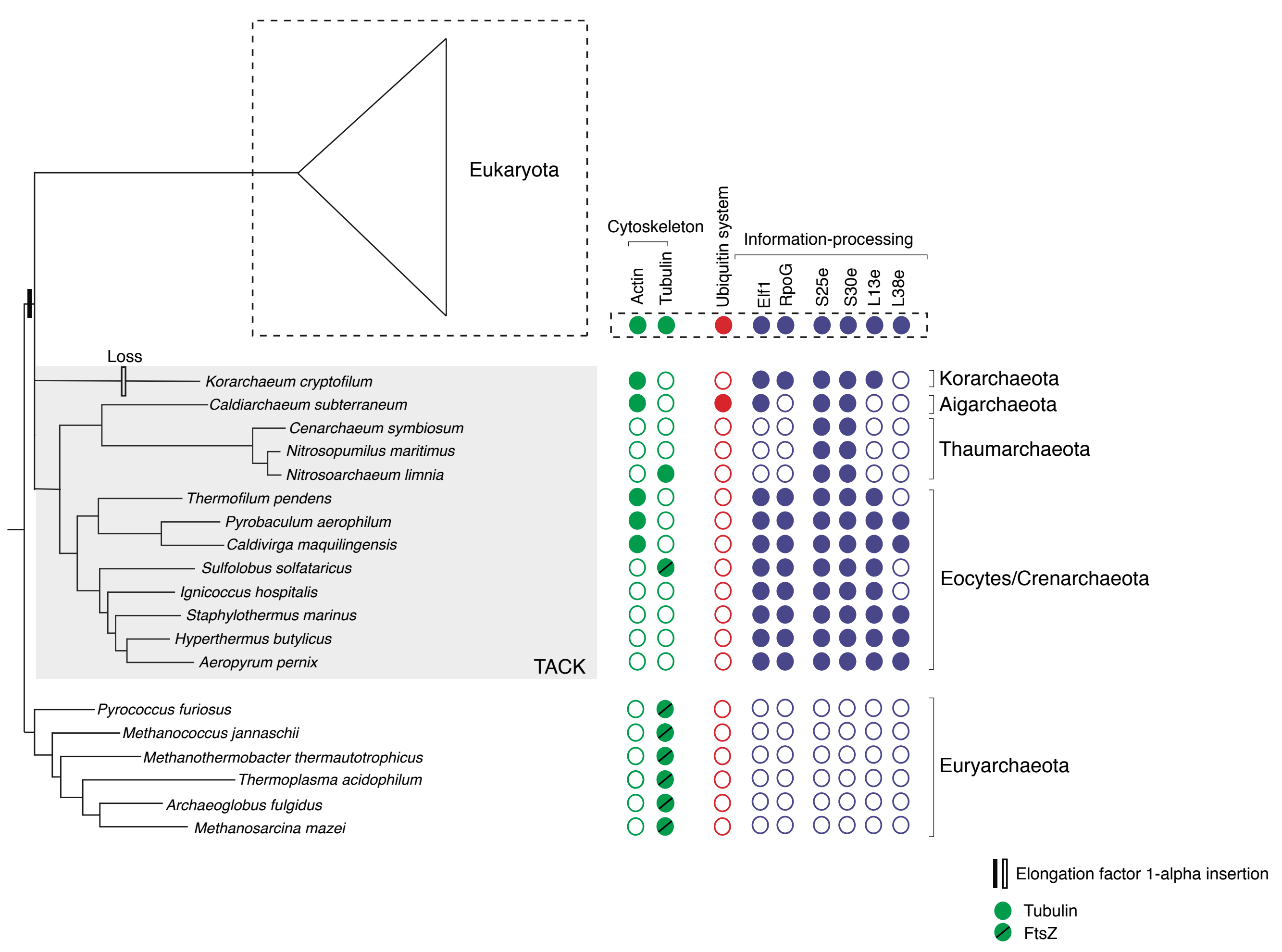

